\title{
Descripción anatómica vegetativa de dos especies de Nymphoides (Menyanthaceae)
}

\section{Vegetative anatomy of two Nymphoides species (Menyanthaceae)}

\author{
Mahinda Martínez* y Maricela Gómez Sánchez \\ Escuela de Biología, Universidad Autónoma de Querétaro. Avenida de las Ciencias s/n, 76230 Juriquilla, Querétaro. \\ *Correspondencia: mahinda@uaq.mx
}

\begin{abstract}
Resumen. En México crecen dos especies de Nymphoides, $N$. indica y $N$. fallax. El conocimiento de la anatomía del género es incompleto y $N$. fallax no se ha tratado. Este trabajo presenta la descripción anatómica de ambas, a partir de cortes con micrótomo, a mano libre y diafanizados. La raíz tiene la superficie cubierta por una exodermis de varias capas de células con una sustancia mucilaginosa, con un córtex primario compuesto de células redondeadas sin espacios intercelulares en $N$. fallax y escasos en $N$. indica, con abundante inulina como material de reserva; el sistema vascular tiene de 9 a 10 cordones de xilema poliarco que alternan con el floema, hay una endodermis bien definida. El tallo muestra aerénquima y astrosclereidas. La hoja tiene estomas anomocíticos en la epidermis superior e hidropoten abundante en el envés; la venación de la lámina es actinódroma flavelada con las terminaciones modificadas a hidatodos y abundantes astroesclereidas en pecíolo y lámina. En corte transversal, la lámina tiene epidermis uniseriada, parénquima en empalizada de tres a cinco estratos de células y aerénquima hacia el lado inferior y esclereidas abundantes. La exodermis multicelular mucilaginosa no se había descrito con anterioridad y los cristales citados por otros autores están ausentes.
\end{abstract}

Palabras clave: anatomía, raíz, tallos, hojas.

\begin{abstract}
Two species of Nymphoides grow in Mexico, N. indica and N. fallax. Since only a few species in the genus have been anatomically studied, we worked on the vegetative anatomy of both species and N. fallax is studied for the first time. We describe the anatomy of both, as seen in slides obtained through microtome, by free hand and transparentations. We found the root surface covered by several exodermis layers with a mucilaginous secretion; the primary cortex is constituted by rounded cells and lacks intercellular spaces in $N$. fallax, whereas $N$. indica has only a few, the cells contain abundant inuline for storage; the vascular system is composed from 9 to 10 xylem strands of a polyarch xilem, alternate with the phloem; it has a well defined endodermis. The stem has abundant aerenchyma and astrosclereids. Leaves have anomocytic stomata on the adaxial side, and abundant hydropoten on the abaxial; venation is actinodrome flavelated with the terminal portions modified to water pores; branched sclerenchyma present as idioblasts are common. In transverse section, the lamina has a simple epidermis, a mesophyll differentiated in a palisade parenchyma three to five layers thick, and a spongy mesophyll with large abundant air cavities in the abaxial side, astrosclereids are abundant. The mucilaginous exodermis had not previously been described, and the oxalate crystals described by other authors were not found.
\end{abstract}

Key words: anatomy, roots, stems, leaves.

\section{Introducción}

Nymphoides es un género de 22 especies de plantas acuáticas de distribución cosmopolita. Son plantas herbáceas perennes o rara vez anuales de hojas flotantes que crecen en cuerpos de agua dulce permanentes o temporales. Metcalfe y Chalk (1950) estudiaron la anatomía de la familia (como subfamilia Menyanthoideae de la familia Gentianaceae), a excepción de Nymphoides.

Raynal (1974), a partir de las 13 especies que se desarrollan en África y Madagascar, consideró la arquitectura de la planta de Nymphoides como aquella formada por

Recibido: 10 enero 2005; aceptado: 17 marzo 2006 dos estructuras caulinares en el mismo individuo; una compuesta por el órgano vegetativo enraizado monopodial no florífero, con entrenudos muy pequeños, y la otra por los tallos floríferos flotantes que se producen simpodialmente en entrenudos muy alargados. La estructura que emerge del rizoma en $N$. indica, la interpreta como tallos, mientras que la que aparece después de la inflorescencia y de las raíces adventicias la considera un pecíolo (Fig. 1).

Conard (1937) describe la anatomía de las raíces adventicias de $N$. aquaticum, señalando la presencia de abundantes granos de inulina como sustancia de reserva en el cortex. Sculthorpe (1967) señala en su descripción de las hojas flotantes, que Nymphoides tiene esclereidas en hojas, pecíolo, órganos subterráneos, flores y frutos; los estomas están 


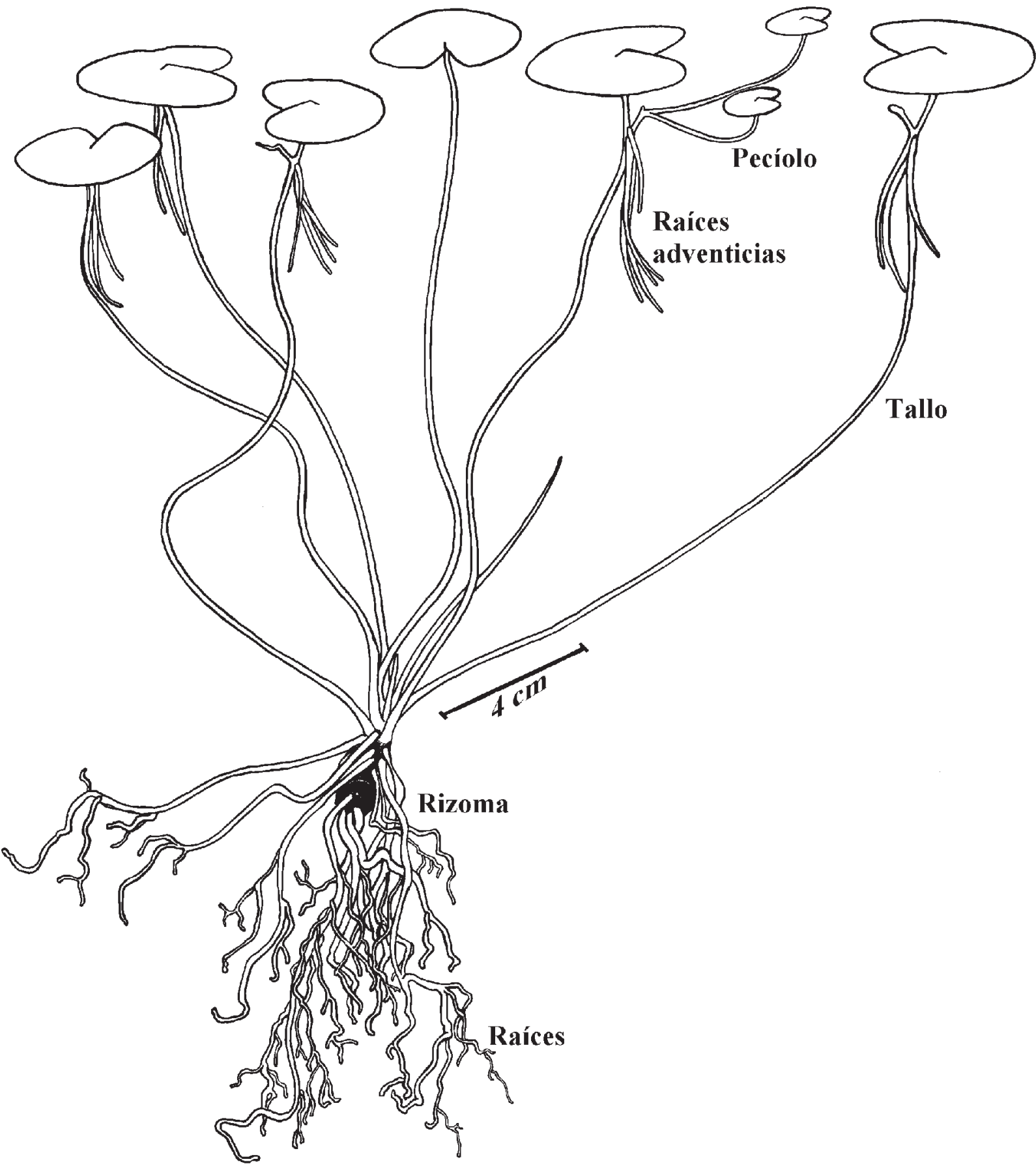

Figura 1. Morfología de Nymphoides fallax, adaptada de Raynal (1974) para N. indica.

restringidos a la epidermis superior de las hojas y describe la presencia de hidatodos (estomas poco diferenciados sin el mecanismo de apertura y cierre, Esau, 1976, p. 344) en la superficie inferior en los márgenes de la hoja. Raynal (1974) describió la morfología de Nymphoides de África y Madagascar e incluyó diagramas de cortes transversales de tallo, pecíolo, hojas y frutos, así como descripciones de la ornamentación de las semillas. Muestra un esquema simplificado de un corte transversal de tallo y pecíolo, en el que el tallo tiene un contorno circular con un haz vascular central rodeado por aerénquima con haces vasculares más pequeños y dispersos. El pecíolo es una estructura hendida con tres haces vasculares principales formando un arco, con haces más pequeños en la periferia. Para la lámina, el autor 
consignó tres consistencias que corresponden a anatomías diferentes. Las hojas papiráceas de $N$. elegans tienen escaso desarrollo del aerénquima y por debajo del tejido vascular; $N$. indica tiene consistencia coriácea, como la mayoría de las especies, y esto corresponde a un parénquima en empalizada bien desarrollado, y un sistema lagunar pequeño por encima del haz vascular y fuertemente desarrollado debajo del haz vascular. Finalmente, N. ezannoi, de consistencia esponjosa en el envés, corresponde a un aerénquima mucho más desarrollado que el parénquima en empalizada. Describe también la presencia de grupos verrugosos en la epidermis de todas las estructuras sumergidas.

Para N. indica, Gattuso y Gattusso (1989) estudiaron la exomorfología y anatomía, concluyendo también que los ejes ascendentes son tallos que terminan en una porción contraída que representa un nudo con una hoja tectriz flotante y un braquiblasto en la axila con brácteas, primordios florales, raíces adventicias y estolones. La descripción de la hoja concuerda con la de los autores anteriores, pero en el eje ascendente o estolón (equivalente a lo que en este trabajo se describe como tallo) encuentran dos haces vasculares enfrentados por el xilema y la presencia de una endodermis. En la raíz arraigada describen amplias cavidades aeríferas. No señalan la presencia de sustancias de reserva, pero encuentran cristales de oxalato de calcio y tricoesclereidas en todos los órganos, así como hidropoten en tallo, hojas, brácteas y raíces adventicias flotantes.

En México crecen dos especies de Nymphoides, $N$. indica (L.) O. Kuntze y N. fallax Ornduff; la primera es de flores blancas y se distribuye en los trópicos del Viejo y Nuevo Mundo. En México se encuentra de 0 a 1000 m snm (Lot et al., 1999), la segunda tiene flores amarillas, es endémica de México y Guatemala y se localiza en zonas montañosas por arriba de los 1500 m (Ornduff, 1969). El objetivo de este trabajo es describir la anatomía vegetativa de ambas especies, especialmente de $N$. fallax que no se ha tratado con anterioridad, contribuyendo así al conocimiento de la anatomía del género.

\section{Materiales y métodos}

Las plantas se colectaron en los estados de Tamaulipas ( $N$. indica, Municipio de Aldama, poblado de Nuevo Progreso, A. Mora s/n, Instituto de Ecología y Alimentos, Universidad Autónoma de Tamaulipas, herbario UAT, y M. Martínez $s / n$, Licenciatura en Biología, Universidad Autónoma de Querétaro, herbario QMEX) y de Querétaro (N. fallax, Municipio de Amealco, cerca de San Ildefonso, M. Martínez 6239, QMEX y Municipio de Huimilpan, en las afueras de Huimilpan, M. Martínez 5918, QMEX). Parte del material se fijó en campo y parte se mantuvo vivo en el invernadero para hacer observaciones adicionales. Se hicieron cortes en plantas maduras con flores de dos individuos, provenientes de dos localidades para ambas especies. En las raíces ancladas y adventicias, los cortes se hicieron en la zona madura y en el tallo aéreo; se usaron porciones de la lámina media en hojas maduras y jóvenes, y en el pecíolo el corte se hizo por debajo de la lámina. Las descripciones siguen los criterios y nomenclatura de Radford et al. (1974) y Font Quer (1982).

Las plantas se fijaron en Navashin (Johansen, 1940), a las 24 horas se almacenaron en alcohol 70\%. Para hacer los cortes histológicos, se deshidrataron en una serie de alcohol etílico-alcohol terbutílico (Johansen, 1940) y se incluyeron en parafina. Los cortes se tiñeron con safranina-verde rápido. Se diafanizó con alcohol 80\%-hidróxido de sodio 10 \% y se tiñeron con fucsina y verde rápido (Fuchs, 1963). Los disociados se hicieron con solución de Jeffrey (Johansen, 1940). Para el microscopio electrónico de barrido (MEB), se fijaron en alcohol al $70 \%$ pecíolos de ambas especies, se deshidrataron en una serie de alcohol-acetona, se secaron a punto crítico y se recubrieron con oro. Los cortes se hicieron en un micrótomo de rotación Leica a 12 micras, las fotografías se tomaron en un microscopio Zeiss Axiostar con una cámara Zeiss MC80. La observación de los granos de inulina se hizo en cortes a mano libre montados en gelatina glicerinada teñidos con lugol. Las preparaciones fijas se encuentran en la Escuela de Biología, UAQ.

\section{Resultados}

Las descripciones corresponden a ambas especies a menos que se indique lo contrario, ya que son pocas las diferencias entre las estructuras estudiadas.

Raíz arraigada y aérea. La superficie de la raíz está cubierta por una exodermis de varias capas celulares que contienen una sustancia mucilaginosa (Fig. 2 A). El cortex primario está compuesto de células redondeadas de tamaño variable, espacios intercelulares rara vez presentes en $N$. indica, poco abundantes y pequeños, y ausentes en $N$. fallax (Fig. 2 A). Las células de la raíz madura tienen abundantes granos (Fig. 2 C) como material de reserva, que según Conard (1937) son de inulina. La endodermis es uniestratosa bien definida y conspicua, no se distingue un periciclo (Fig. 2 B). El sistema vascular está compuesto de numerosos cordones de xilema (9-10), los vasos presentan poco a mucho engrosamiento secundario, el xilema es poliarco, alternando con paquetes de floema. La raíz aérea tiene una estructura similar a la arraigada, pero con tejido fotosintético.

Tallo. En un corte transversal de tallo, la epidermis es uniseriada. Por debajo de la epidermis, el cortex está compuesto de 3 a 5 hileras de células de parénquima de forma redonda e isodiamétrica y de tamaño variable cercanas a la epidermis. Entre la epidermis y los haces vasculares, se forma un aerénquima ampliamente lagunar, con un número mayor de hileras de células (Fig. 3 A). En esta región hay abundantes idioblastos esclerenquimatosos ramificados (astrosclereidas, Font Quer, 1982, Figs. 3 B y C). Los haces vasculares están ampliamente espaciados y ubicados 


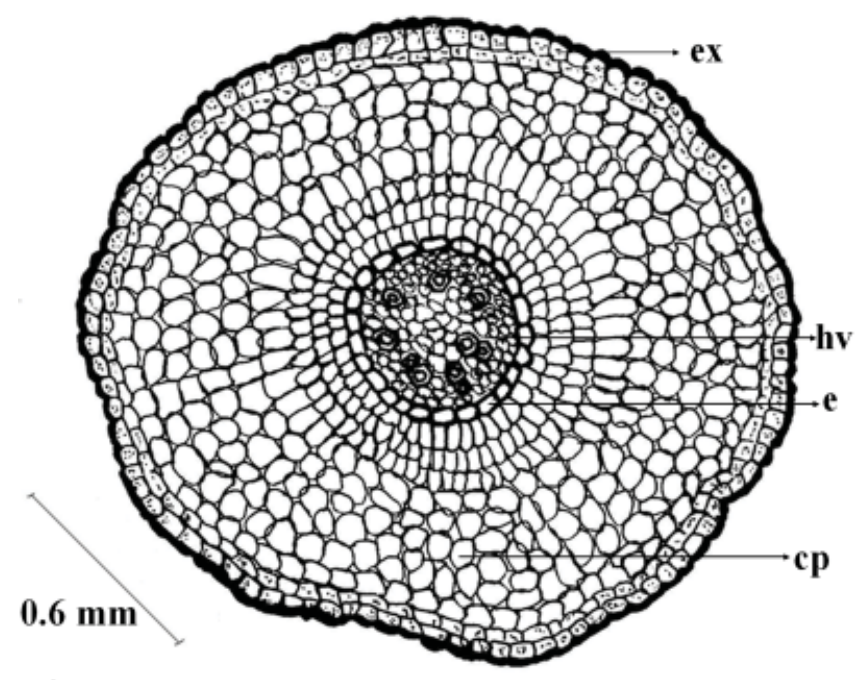

A

Figura 2A. Raíz, corte transversal completo. ex $=$ exodermis, $\mathrm{cp}$ $=$ córtex primario, $\mathrm{e}=$ endodermis, $\mathrm{hv}=$ tejido vascular.

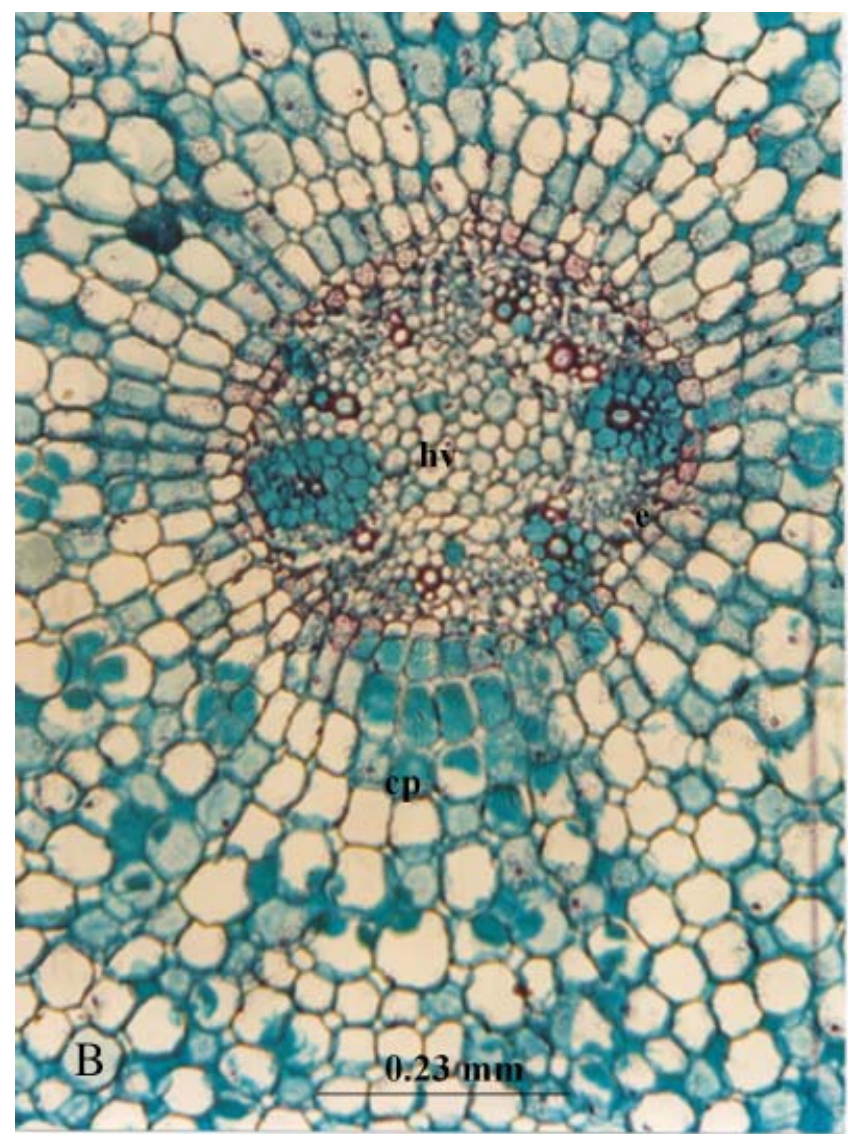

Figura 2B. Raíz, corte transversal, detalle de la endodermis y el córtex primario. $\mathrm{cp}=$ córtex primario, $\mathrm{e}=$ endodermis, $\mathrm{hv}=$ tejido vascular.

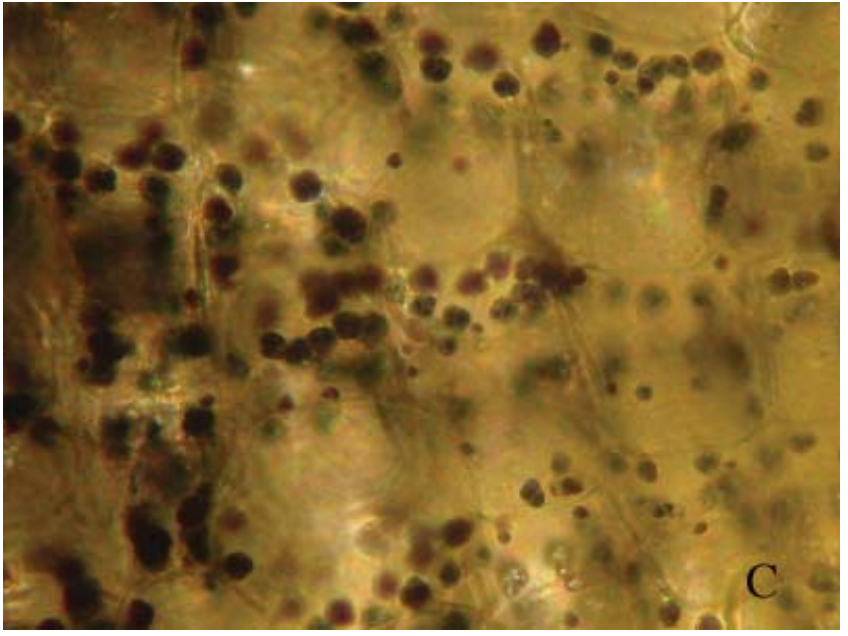

Figura 2C. Raíz, corte transversal, detalle del córtex con granos de inulina.

en un círculo definido en el tejido cortical; el haz vascular central es considerablemente más grande que los demás y el diámetro de los vasos va disminuyendo hacia la periferia. En todos, el xilema está compuesto por un solo vaso y el floema rodea parcial o completamente al xilema. El diámetro de los vasos mide en promedio $0.04 \mathrm{~mm}$ en el haz vascular central, en los medianos $0.03 \mathrm{~mm}$ y en los pequeños $0.02 \mathrm{~mm}$.

Hoja. El pecíolo tiene una epidermis uniseriada, los haces vasculares esparcidos y ubicados en un círculo definido de tejido parenquimatoso rodeando al aerénquima. El haz vascular central es más grande que los demás, y está rodeado por abundante aerénquima. Las astrosclereidas son abundantes (Fig. 4 B) en hojas maduras, pero ausentes en hojas jóvenes.

La lámina diafanizada permitió reconocer la venación actinódroma flabelada; las venas de diferentes órdenes forman una retícula que constituye aréolas imperfectas (Fig. 4 A); las venulas son simples; hay astrosclereidas abundantes en toda la lámina, concentrándose en el pecíolo (Fig. 4 A, B, C). Grupos de células pequeñas y abultadas (hidropoten, sensu Mayr, 1915, citado por Sculthorpe, 1967), abundantes en el envés (Fig. 4 C). La última vena marginal y las terminaciones de las venas laterales están modificadas en hidatodos (Fig. 4 C). Los engrosamientos del xilema son de tipo anular y helicoidal (Fig. 5 A). La epidermis superior presenta estomas anomocíticos.

En corte transversal, la lámina tiene una epidermis uniseriada de paredes delgadas en haz y envés, los estomas están sólo en el haz, mientras que el envés presenta abundante hidropoten. El mesófilo está bien diferenciado en parénquima en empalizada y esponjoso. El parénquima en empalizada presenta 3 estratos, llegando a encontrarse hasta 5 en algunas regiones de la hoja con cámaras de aerénquima pequeñas (Fig. 5 B). Hacia el lado inferior en el parénquima esponjoso se observan grandes cámaras de aire formando un 


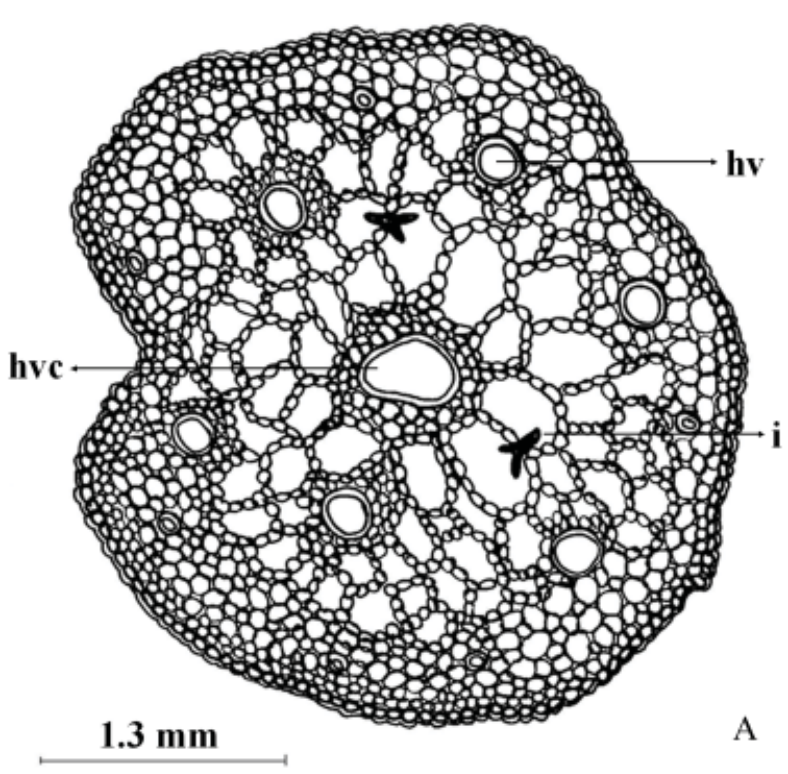

Figura 3A. Tallo, corte transrversal. hv $=$ haz vascular, hvc $=$ haz vascular central, $\mathrm{i}=$ idioblasto esclerenquimatoso (astrosclereida) Los círculos dobles corresponden a vasos.

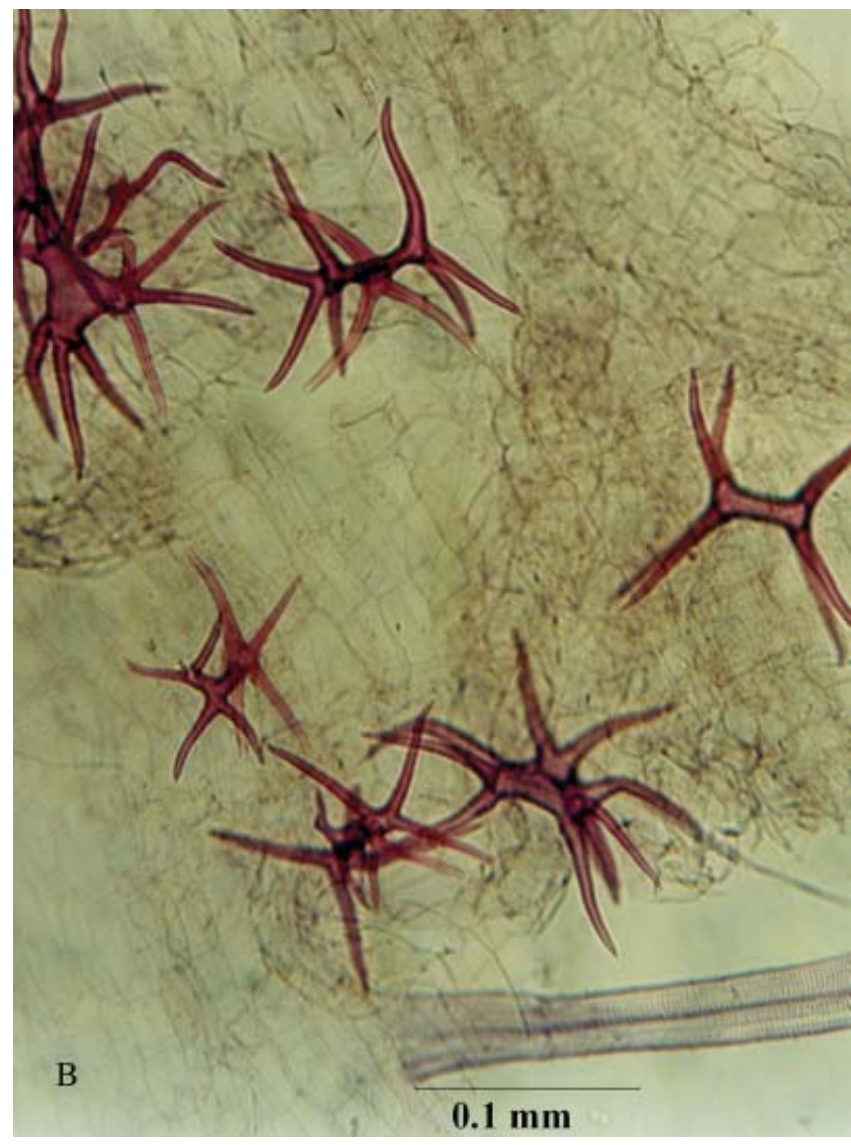

Figura 3B. Tallo, astrosclereidas.

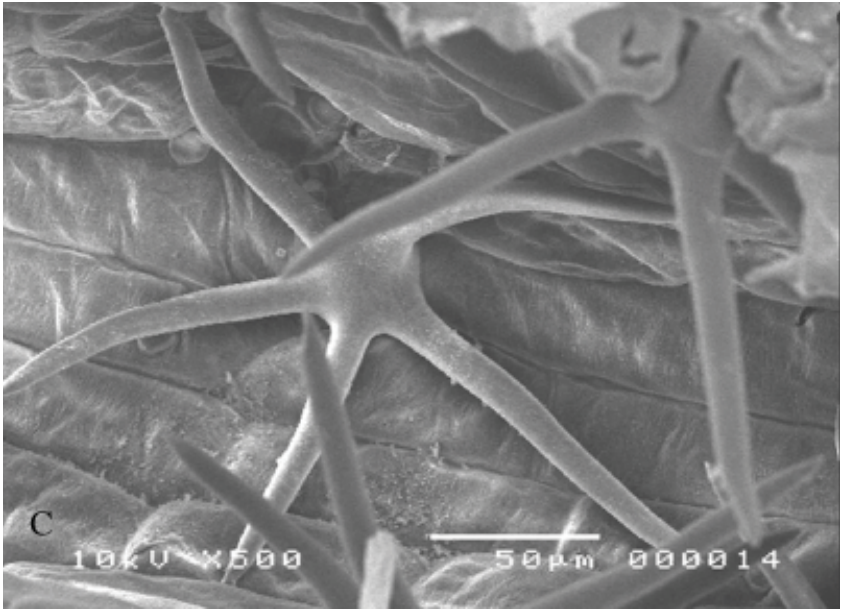

Figura 3C. Tallo, detalle de las astrosclereidas al MEB.

aerénquima abundante. Las astrosclereidas con las ramas o brazos proyectándose al interior de los espacios aéreos del mesófilo son más abundantes hacia la base de la hoja y en hojas maduras, pero están ausentes en el ápice y en hojas inmaduras.

\section{Discusión y conclusiones}

Ambas especies tienen la anatomía típica de una planta acuática y no se distinguen entre sí. Se observa abundante desarrollo de aerénquima en todas sus partes, excepto en la raíz adventicia de ambas especies y en la arraigada de $N$. fallax, presencia de hidatodos en las terminaciones de la venación de las hojas y presencia de hidropoten en el envés.

La anatomía de la raíz de las dos especies de Nymphoides concuerda con la descrita por Conard (1937) para las raíces adventicias de Nymphoides aquaticum, con excepción de pequeños espacios intercelulares cuadrangulares en el córtex que no se observaron en N. fallax. Gattuso y Gattuso (1989) también encontraron espacios en la raíz arraigada de $N$. indica que describen como amplias, pero que los encontramos rara vez y pequeños. La presencia de una sustancia mucilaginosa en la exodermis, sólo se había registrado en la familia para Nephrophyllidium crista-galli Gild (Metcalfe y Chalk, 1950), y no la mencionan Conard (1937) ni Gattuso y Gattuso (1989). Sculthorpe (1967) señala la presencia de idioblastos esclerenquimatosos en órganos subterráneos, mismos que Conard (1937) y Gattuso y Gattuso (1989) no describen, y nosotras tampoco los observamos. En las especies estudiadas aquí, los idioblastos se observaron exclusivamente en tallos, pecíolos y láminas, todos en estado maduro. Estas observaciones concuerdan con las de Gattuso y Gattuso (1989) y las de Raynal (1974).

A pesar de que Raynal (1974) describe la diferencia de tallos y pecíolos en $N$. indica, sus esquemas no corresponden 


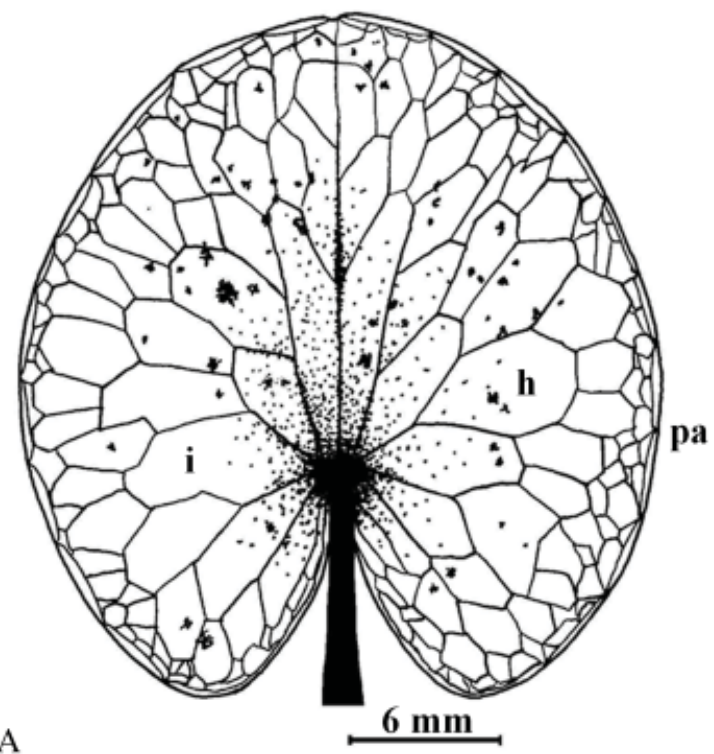

Figura 4A. Hoja, diafanizado. $\mathrm{h}=$ hidropoten, $\mathrm{i}=$ idioblastos esclerenquimatosos, $\mathrm{pa}=$ poro de agua (hidatodos).

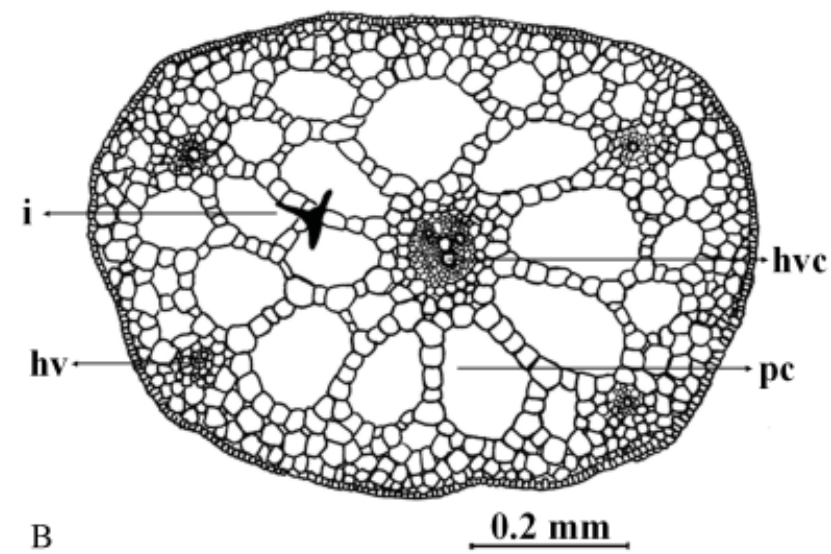

Figura 4B. Hoja, corte transversal de pecíolo. $\mathrm{i}=$ idioblastos esclerenquimatosos, $\mathrm{hv}=$ haz vascular, hvc $=$ haz vascular central $\mathrm{pc}=$ parénquima cortical o aerénquima.

con lo que señalamos aquí, ya que en la misma especie encontramos para el tallo, la distribución de tejidos y el arco de haces vasculares que ella dibuja para el pecíolo, a pesar de que cuidamos que la muestra estudiada del pecíolo correspondiera a la zona inmediatamente inferior a la lámina. Esta discrepancia podría deberse a la altura de la planta de la que se tomó la muestra para el corte de tallo, y tal vez lo que describe Raynal como tallo aéreo proviene de una zona más cercana al rizoma. También difiere nuestra descripción del tallo de la de Gattuso y Gattuso (1989), quienes encontraron el haz vascular central compuesto por dos haces enfrentados por el xilema y limitados por una endodermis, mientras que

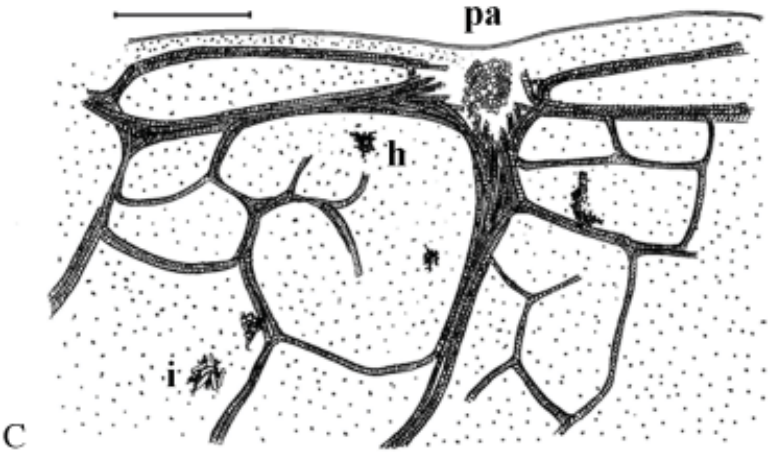

Figura 4C. Hoja, acercamiento del poro de agua. $\mathrm{h}=$ hidropoten, $\mathrm{i}$ $=$ idioblastos esclerenquimatosos, $\mathrm{pa}=$ poro de agua (hidatodos).

nosotras encontramos un haz vascular central típico y sin endodermis, una condición más común para los tallos.

Las hojas de las dos especies corresponden a la descrita por Raynal (1974) para las hojas de consistencia coriácea, con un aerénquima bien desarrollado y un parénquima en empalizada de varias células de espesor. Los cuerpos verrucosos de Raynal (1974) seguramente corresponden a lo que describimos como hidropoten. En ambas especies se muestran exclusivamente en el envés de la lámina y no en el resto de las partes vegetativas de la planta, aunque también Gattuso y Gattuso (1989) los encuentran en todos los órganos excepto el rizoma y las raíces arraigadas. Finalmente, Gattuso y Gattuso (1989) señalan la presencia de abundantes cristales de oxalato de calcio en todos los órganos, mientras que nosotras no los encontramos en ningún tejido de las dos especies, coincidiendo con Raynal (1974) que no los menciona y Metcalfe y Chalk (1950) quienes indican su ausencia.

\section{Agradecimientos}

A la Dra. Teresa Terrazas por revisar el manuscrito. A Aslam Narváez Parra por los dibujos de la planta y la figura 4 , y a tres revisores anónimos sus comentarios.

\section{Literatura citada}

Conard, H. S. 1937. The banana floatingheart (Nymphoides aquaticum). Proceedings of the Iowa Academy of Science 44: 61-64.

Esau, K. 1976. Anatomía vegetal. Omega, Barcelona. p. 344.

Font Quer, P. 1982. Diccionario de botánica. Labor, Barcelona.1244 pp.

Fuchs, C. 1963. Fucsin staining with $\mathrm{NaOH}$ clearing for lignified elements of whole plants or plant organs. Stain technology 39:141-144.

Gattuso, M. y S. Gattusso. 1989. Exomorfología y anatomía 


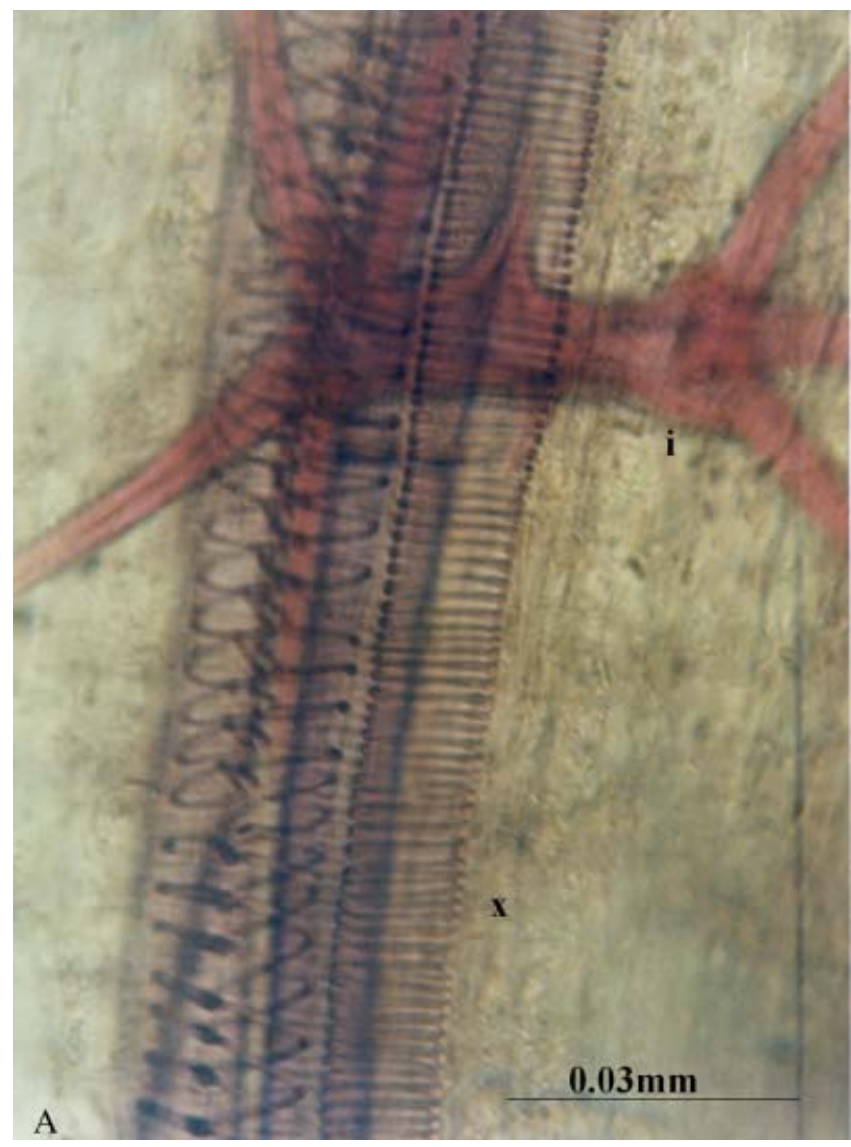

Figura 5A. Hoja, diafanizado con engrosamiento del xilema de tipo anular. $\mathrm{i}=$ idioblasto, $\mathrm{x}=$ xilema.

de Nymphoides indica (L.) O. Kuntze (Menyanthaceae). Parodiana 5:249-259.

Johansen, D.A. 1940. Plant microtechnique. McGraw-Hill, New York y Londres. 523 p.

Lot, A., A. Novelo, M. Olvera y P. Ramírez. 1999. Catálogo de angiospermas acuáticas de México. Hidrófitas estrictas emergentes, sumergidas y flotantes. Cuadernos 33, Instituto de Biología, UNAM, México, D.F. p. 89-91.

Metcalfe, C. R. y L. Chalk. 1950. Anatomy of the dicotyledons. Claredon, Oxford. II:936-939.

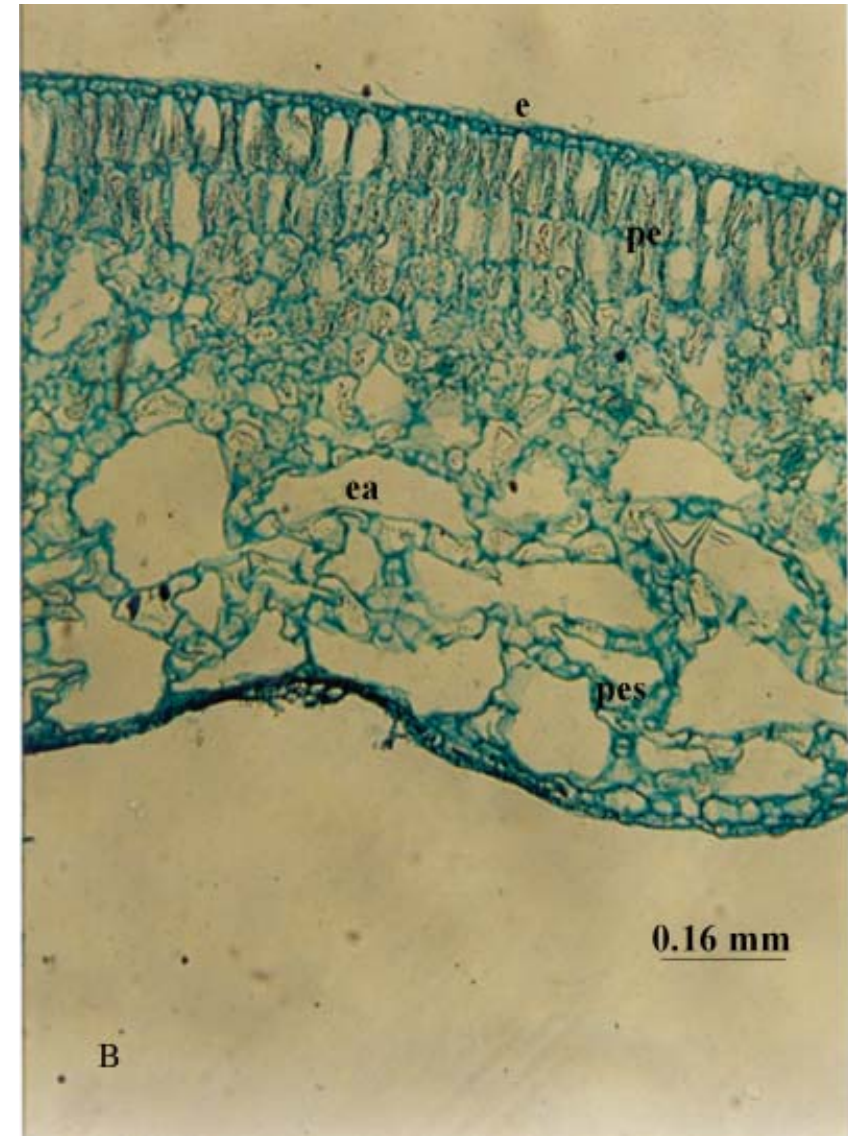

Figura 5B. Hoja, corte transversal de la lámina. e = estoma, ea = espacio aéreo intercelular, pe = parénquima en empalizada o clorénquima, pes = parénquima esponjoso.

Ornduff, R. 1969. Neotropical Nymphoides (Menyanthaceae): Mesoamerican and West Indian species. Brittonia 21: 346-352.

Radford, A. E., W. C. Dickinson, J. R. Massey, C. R. Bell. 1974. Vascular plant systematics. Harper et Row, London. 891 p.

Raynal, A. 1974. Le genere Nymphoides (Menyanthaceae) en Afrique et a Madagascar. Adansonia, ser. 2, 14 (2):227-270.

Sculthorpe, C. D. 1967. The biology of aquatic vascular plants. St. Martin's, New York, p. 84-91. 